\title{
Valuasi Ekonomi Ekosistem Hutan Mangrove Di Desa Betahwalang, Kecamatan Bonang, Kabupaten Demak, Jawa Tengah
}

\author{
Bellatris Santri*, Rudhi Pribadi, Irwani \\ Departemen IImu Kelautan, Fakultas Perikanan dan IImu Kelautan, Universitas Diponegoro \\ JI. Prof. H. Soedarto S.H, Tembalang, Semarang, Jawa Tengah 50275 Indonesia \\ ${ }^{*}$ Corresponding author, e-mail : bellatrisant.gmail.com
}

\begin{abstract}
ABSTRAK: Ekosistem hutan mangrove memiliki 3 fungsi utama yaitu fungsi fisik, fungsi ekologis dan fungsi ekonomi. Pemanfaatan ekosistem mangrove semakin meningkat sehingga menyebabkan kerusakan dan penurunan jasa lingkungan. Untuk menghindari hilangnya fungsi ekosistem hutan mangrove maka perlu dilakukan konservasi mangrove dengan upaya rehabilitasi. Perhitungan valuasi ekonomi untuk mengetahui kerugian dari hilangnya nilai ekonomi ekosistem hutan mangrove. Tujuan dari penelitian ini adalah mengetahui nilai guna (use value) maupun nilai non guna (non use value) dan nilai ekonomi total ekosistem hutan mangrove di Desa Betahwalang, Kecamatan Bonang, Kabupaten Demak. Metode yang digunakan dalam penelitian ini adalah metode deskriptif eksploratif yang ditekankan pada kuantifikasi total nilai pemanfaatan langsung maupun tidak langsung ekosistem hutan mangrove. Sampel penelitian yang diambil adalah masyarakat yang mempunyai mata pencaharian berkaitan dengan keberadaan ekosistem hutan mangrove secara langsung dan tidak langsung. Hasil penelitian menunjukkan nilai ekonomi total ekosistem hutan mangrove di Desa Betahwalang adalah sebesar Rp 1.510.046.534/tahun yang didapatkan dari nilai guna (use value) sebesar Rp 817.443.034,35/tahun dan nilai non guna (non use value) sebesar Rp 692.603.500/tahun.
\end{abstract}

Kata kunci: Ekosistem Mangrove, Konservasi, Valuasi Ekonomi, Betahwalang

\section{Economic Valuation of Mangrove Forest Ecosystem in Betahwalang Village, Bonang District, Demak Regency, Central Java.}

\begin{abstract}
The mangrove forest ecosystem is an ecosystem located along the coast or river estuary that is influenced by the tide of sea water. The existence of this ecosystem has a very important role in the surrounding environment, either directly or undirectly. The Mangrove forest ecosystem has 3 main functions, physical, ecological and economic function. The utilization of mangrove ecosystem by the community is increasing and causing damage to the mangrove forest ecosystem. To avoid the loss of ecosystem function of mangrove forest, it needs to be renewed with mangrove rehabilitation. Calculation of economic valuation to determine the loss of economic value of the mangrove forest ecosystem if its existence is not maintained properly. This research has purposes for knowing the use value or non use value and the total economic value of the mangrove forest ecosystem in Betahwalang Village, Bonang District, Demak Regency. The methods used in this research are descriptive and explorative method that is emphasized on quantifying the total value of direct or undirect utilization of mangrove forest ecosystems. The method of discourse is used to describe the socio-economic activities of the community and the condition of mangrove forest ecosystem through interviews. Exploratory method is a method to find out the problems that exist in the community and natural phenomena that can affect the existence of economic value of the mangrove forest ecosystem. The results showed the total economic value of the mangrove forest ecosystem in the Betahwalang village is Rp. 1.510.046.534/year consisting of use value of $R p$. 817.443.034.35/year and non use value $R p$ 692.603.500/year. The use value includes direct use value $R p$ 800.275.000/year and option value $R p$ 17.168.034.35/year. The non use value include existence value $R p$ 612.576.000/year and bequest value $R p$ 80.027.500/year.
\end{abstract}

Keywords: Mangrove Ecosystem, Conservation, Economic Valuation, Betahwalang 


\section{PENDAHULUAN}

Ekosistem pesisir seperti hutan mangrove, padang lamun dan terumbu karang merupakan kekayaan dan keanekaragaman hayati (biodiviersity) terbesar di dunia. Sumberdaya alam laut tersebut, merupakan salah satu potensi ekonomi yang memberikan kontribusi besar sebagai pemasok energi penting bagi biota dan lingkungan di sekitarnya (Ekosafitri et al., 2017). Ekosistem hutan mangrove merupakan suatu ekosistem alamiah yang tumbuh dengan baik di daerah pasang surut air laut yang memiliki fungsi fisik sebagai peredam gelombang, pencegah intrusi air laut, erosi dan abrasi pantai. Fungsi ekologis sebagai tempat mencari makan (feeding ground), tempat pemijahan (spawning ground) dan tempat asuhan (nursery ground) bagi biota yang tinggal di sekitarnya. Sedangkan fungsi ekonomis hutan mangrove sebagai tempat ekowisata mangrove, sumber perikanan, sumber oksigen, sumber pangan, penghasil kayu bakar, pewarna batik dan lainlain (Isman et al., 2018). Ekosistem mangrove memiliki peranan penting bagi kehidupan makhluk hidup dikarenakan ekosistem hutan mangrove memiliki sumberdaya hayati yang sangat dibutuhkan untuk kesejahteraan manusia (Tuwo, 2011).

Daerah pesisir meliputi sungai, estuari dan badan air lainnya sangat rentan terhadap perubahan dalam ekosistem, biasanya diakibatkan oleh kegiatan antropogenik yang dapat membahayakan habitat ikan dan organisme air lainnya (Gholizadeh et al., 2016). Kerusakan ekosistem hutan mangrove disebabkan oleh faktor alam dan manusia. Faktor manusia merupakan faktor yang dominan penyebab rusaknya ekosistem hutan mangrove. Menurut Yuliani dan Herminasari (2017) eksploitasi berlebihan dengan melakukan penebangan pohon mangrove sering dilakukan oleh masyarakat. Pembukaan tambak-tambak untuk budidaya ikan, bandeng dan kepiting mengakibatkan adanya perubahan tata guna lahan dan pemanfaatan sumberdaya alam secara berlebihan. Pada akhirnya rusaknya ekosistem hutan mangrove berdampak buruk terhadap sejumlah masalah seperti tingkat abrasi yang tinggi, kerusakan rumah dan sarana jalan di pesisir pantai, menurunnya jumlah tangkapan ikan, udang dan kepiting serta masalah sosial ekonomi lain yang dirasakan oleh masyarakat setempat. Minimnya kesadaran masyarakat akan fungsi dan manfaat ekosistem hutan mangrove bagi manusia menyebabkan keberadaan ekosistem hutan mangrove sangat mengkhawatirkan. Ekosistem hutan mangrove yang dimanfaatkan secara terus menerus mengakibatkan degradasi lingkungan yang cukup parah. Saat ini kebanyakan para pengambil keputusan hanya memperhatikan nilai manfaat langsung tanpa melihat nilai total ekonomi dari ekosistem hutan mangrove. Oleh sebab itu banyak masyarakat yang mengkonversi ekosistem hutan mangrove untuk kepentingan lain (Zen dan Ulfah, 2013).

Desa Betahwalang merupakan desa padat penduduk yang secara geografis berbatasan langsung dengan wilayah pesisir. Keberadaan ekosistem hutan mangrove memberikan manfaat yang sangat besar bagi masyarakat terutama dalam segi ekonomi. Selain itu fungsi dan manfaat ekosistem mangrove secara fisik maupun ekologis juga memiliki keterkaitan dengan fungsi ekosistem hutan mangrove secara ekonomi. Melimpahnya sumber daya perikanan dan kelautan diduga karena adanya keterkaitan dengan fungsi ekosistem hutan mangrove sebagai daerah pemijahan dan tempat berkembang biak bagi biota yang hidup disekitarnya. Belum adanya kajian yang lebih komprehensif mengenai nilai ekonomi yang dihasilkan ekosistem hutan mangrove, maka perlu dilakukan perhitungan valuasi ekonomi ekosistem hutan mangrove. Harapannya apabila masyarakat mengetahui adanya nilai-nilai ekonomi tersebut, masyarakat akan lebih menghargai keberadaan ekosistem hutan mangrove sehingga upaya untuk kelestariannya akan lebih mudah dijalankan.

\section{MATERI DAN METODE}

Materi penelitian yang digunakan terdiri dari data hasil pengamatan langsung di lapangan, data-data terkait yang bersumber dari instansi pemerintah maupun data dari masyarakat yang bersinggungan langsung dengan keberadaan ekosistem hutan mangrove serta data-data terkait nilai ekonomi yang bersumber dari instansi pemerintah daerah dan penelitian sejenis mengenai valuasi ekonomi ekosistem hutan mangrove.

Metode yang digunakan dalam penelitian ini adalah metode deskriptif eksploratif yang ditekankan pada kuantifikasi total nilai pemanfaatan langsung maupun tidak langsung ekosistem 
hutan mangrove. Dalam penelitian ini metode deskriptif digunakan untuk menggambarkan kegiatan sosial ekonomi masyarakat serta kondisi ekosistem hutan mangrove melalui wawancara. Penggunaan metode eksploratif untuk menguji hipotesis tertentu dengan melihat variabel, gejala atau keadaan yang terdapat dalam lokasi penelitian (Arikunto, 2002).

Proses seleksi sampel menggunakan teknik purposive sampling. Purposive sampling adalah metode pengambilan sampel tidak secara acak tetapi berdasarkan pertimbangan-pertimbangan tertentu secara sengaja. Menurut Amalia (2011) teknik pengambilan sampel secara purposive sampling adalah teknik pengambilan data dengan alasan tertentu dengan menggunakan pertimbangan identifikasi fungsi dan manfaat ekosistem mangrove. Responden yang diambil dalam penelitian ini sebanyak 150 orang meliputi masyarakat lokal yang melakukan aktivitas sehari-hari berkaitan dengan ekosistem hutan mangrove secara langsung maupun tidak langsung.

Data primer berasal dari pengamatan langsung di lapangan dengan metode wawancara yang mendalam (depth interview) kepada responden berdasarkan daftar pertanyaan yang telah disusun sesuai dengan keperluan analisis dan tujuan penelitian. Menurut Pujihastuti (2010) kuesioner merupakan teknik pengumpulan data primer untuk memperoleh informasi dari responden dengan cara memberi seperangkat pertanyaan atau pernyataan tertulis kepada responden untuk dijawab secara terbuka artinya responden diberi kebebasan penuh untuk memberikan jawaban yang dirasa perlu. Responden berhak dan diberi kesempatan menguraikan jawaban. Melalui kuesioner ini diketahui ada atau tidaknya serta besar kecilnya dampak yang dirasakan oleh responden dengan adanya keberadaan ekosistem hutan mangrove. Data penunjang dikumpulkan dari dinas-dinas setempat serta lembaga-lembaga lain yang berhubungan dengan materi penelitian, maupun yang berasal dari publikasi dan hasil penelitian yang pernah dilakukan terkait dengan materi penelitian.

Penilaian ekonomi dari seluruh manfaat sumberdaya hutan mangrove menggunakan tahap pendekatan seperti dilakukan oleh Ruitenbeek (1991). Nilai guna langsung merupakan jenis manfaat yang langsung diperoleh dari ekosistem hutan mangrove atau sebagai bentuk manfaat aktual yang dilakukan oleh masyarakat.

$$
\text { DUV }=\text { DUV1 + DUV2 + DUV3.... + DUVn (Rp/tahun) }
$$

Keterangan : DUV1 = Manfaat langsung, total dari hasil penangkapan kepiting; DUV2 = Manfaat langsung, total dari hasil penangkapan rajungan; DUV3 = Manfaat langsung, total dari hasil penangkapan ikan; DUV4 = Manfaat langsung, total dari hasil tambak udang; DUV5 = Manfaat langsung, total dari hasil tambak bandeng; DUV6 = Manfaat langsung, total dari hasil tambak garam; DUV7 = Manfaat langsung,total dari hasil produksi ikan asin

Nilai pilihan mengacu pada nilai keanekaragaman hayati (biodiversity) hutan mangrove di Indonesia termasuk di Desa Betahwalang sebesar USD 1.500 per $\mathrm{km}^{2}$ per tahun atau sebesar USD 15 per ha per tahun.

Keterangan: OV $\begin{aligned} \text { OV }=\text { US } \$ 15 \\ =\text { Option Value }\end{aligned}$

Manfaat keberadaan merupakan manfaat yang dirasakan oleh masyarakat terkait keberadaan eksosistem mangrove. Penentuan nilai manfaat keberadaan dapat diketahui dengan metode pendekatan keinginan membayar seseorang (willingness to pay) dengan adanya keberadaan ekosistem hutan mangrove.

$$
\mathrm{EV} \quad=\sum_{1}^{n}=1(\mathrm{EVi}) / \mathrm{n}(\mathrm{Rp} / \mathrm{tahun})
$$

Keterangan : EV = Nilai WTP dari responden ke-I; $\mathrm{n}=$ Jumlah responden

Nilai warisan merupakan nilai ekonomi yang diperoleh dari manfaat ekosistem mangrove yang dapat digunakan untuk generasi mendatang. Perhitungan nilai warisan ekosistem mangrove menggunakan perkiraan nilai warisan yang tidak kurang $10 \%$ dari nilai manfaat langsung hutan mangrove.

$$
\text { BV }=\text { DUV } \times 10 \%
$$

Keterangan : BV = Nilai warisan; DUV = Nilai guna langsung 
Nilai ekonomi total merupakan nilai yang didapat dari penjumlahan nilai guna dan tidak ada nilai guna dari ekosistem hutan mangrove yang telah diidentifikasi dan dikuantifikasikan.

$$
\mathrm{TEV}=\mathrm{DUV}+\mathrm{OV}+\mathrm{EV}+\mathrm{BV}(\mathrm{Rp} / \mathrm{tahun})
$$

Keterangan : TEV = nilai ekonomi total; $\mathrm{DUV}=$ nilai guna langsung; $\mathrm{OP}=$ nilai manfaat pilihan; $\mathrm{EV}$ $=$ nilai keberadaan; $\mathrm{BV}=$ nilai warisan

\section{HASIL DAN PEMBAHASAN}

Kabupaten Demak merupakan salah satu daerah yang memiliki kawasan pesisir dan potensi hutan mangrove dengan luas wilayah sebesar 89,743 ha (Faturrohmah dan Marjuki, 2017). Lokasi penelitian terletak di Desa Betahwalang, Kecamatan Bonang, Kabupaten Demak terletak di daerah pesisir yang memiliki potensi kelautan dan perikanan cukup besar dari perikanan tangkap dan perikanan budidaya. Desa Betahwalang juga memiliki ekosistem hutan mangrove yang cukup luas sebesar 81,332 ha (Ganesa, 2019). Ekosistem hutan mangrove di Desa Betahwalang tumbuh berdampingan dengan pemukiman penduduk. Menurut Purnama, Pribadi dan Soenardjo (2019) terdapat 12 spesies mangrove dari 8 famili yang telah teridentifikasi di Desa Betahwalang yaitu Rhizophora apiculata, Rhizophora mucronata, Avicennia marina, Avicennia alba, Soneratia alba, Soneratia caseolaris, Bruguiera cylindrica. Mangrove minor yaitu Excoecaria agallocha dan mangrove asosiasi yaitu Terminalia catappa, Talipariti tiliaceum, Suaeda maritima dan Acanthus ilicifolius.

Kondisi mangrove di Desa Betahwalang sebagian besar berada di tepi sungai dan di sekitar area tambak. Tambak-tambak tersebut sudah dikelola secara intensif yang dimiliki perseorangan. Namun ada juga tegakan mangrove yang ditemukan pada substrat berlumpur yang berhadapan langsung dengan laut. Berdasarkan wawancara yang dilakukan dengan masyarakat, kondisi ekosistem hutan mangrove di Desa Betahwalang masih terancam kelestariaanya diduga karena banyaknya aktivitas masyarakat yang sering dilakukan disekitar ekosistem hutan mangrove salah satunya yaitu pembukaan lahan tambak untuk kepentingan budidaya. Suhu perairan di Desa Betahwalang berkisar antara $28^{\circ} \mathrm{C}-30^{\circ} \mathrm{C}$. Nilai salinitas berkisar antara $10 \mathrm{ppt}-20 \mathrm{ppt}$ dengan derajat keasaman $(\mathrm{pH})$ 6-7 dan nilai DO berkisar 4,6 -6,8 mg/l.

\section{Nilai Guna Langsung (Direct Use Value/DUV)}

Pemanfaatan ekosistem hutan mangrove secara langsung di Desa Betahwalang sebesar Rp 800.275.000,-/tahun. Nilai guna langsung ekosistem hutan mangrove di Desa Betahwalang mencakup 7 bagian yaitu penangkapan rajungan, penangkapan kepiting bakau, penangkap ikan, tambak udang, tambak bandeng, tambak garam dan penjual ikan asin. Penangkapan rajungan menghasilkan nilai sebesar Rp 46.080.000,- dengan rata-rata produksi per tahun sekitar 1.2 ton. Rajungan merupakan hasil tangkapan utama dan sumber penghasilan utama bagi masyarakat yang berprofesi sebagai nelayan karena Desa Betahwalang merupakan penghasil rajungan terbesar di Indonesia dan sudah berhasil mengekspor rajungan untuk negara-negara di Eropa salah satunya Amerika Serikat. Desa Betahwalang juga ditetapkan sebagai daerah konvervasi rajungan sehingga dalam penangkapannya terdapat aturan-aturan yang berlaku seperti, pelarangan menangkap rajungan di daerah konservasi serta menangkap rajungan yang sedang bertelur demi keberlanjutan populasi rajungan di laut.

Penangkapan kepiting bakau juga merupakan salah satu pendapatan masyarakat Betahwalang. Kegiatan ini biasanya dilakukan pada malam hari dengan memasang jaring pada sekitar ekosistem hutan mangrove. Manfaat penangkapan kepiting menghasilkan nilai sebesar Rp 56.815.000,-/tahun yang diperoleh dari pendapatan bersih nelayan kepiting dengan hasil tangkapan sekitar $951 \mathrm{~kg}$. Dalam sekali penangkapan rata-rata responden mendapatkan $2 \mathrm{~kg}$ dengan harga Rp 65.000,-/kg - Rp 100.000,-/kg yang dijual ke pengepul tergantung besar kecilnya ukuran kepiting yang didapatkan.

Hasil tangkapan yang terdiri dari ikan menghasilkan nilai guna sebesar Rp 24.380.000,-/ha/th. Masyarakat setempat biasanya menjual hasil tangkapan ikan kepada pengepul, namun ada juga masyarakat yang mengolah hasil tangkapan tersebut sebagai ikan asin yang menghasilkan nilai 
guna sebesar Rp 23.000.000,-/tahun. Dengan melimpahnya hasil perikanan di laut, hal ini menunjukkan bahwa Desa Betahwalang memiliki perairan yang subur sehingga hasil perikanan yang diperoleh sangat melimpah. Kondisi seperti ini erat kaitannya dengan keberadaan ekosistem hutan mangrove yang berfungsi sebagai tempat pemijahan ikan maupun biota laut disekitarnya. Namun, jika ekosistem hutan mangrove mengalami degradasi atau hilang maka penurunan hasil produksi ikan akan menurun. Ketika ekosistem hutan mangrove itu rusak atau tidak berfungsi seperti seharusnya maka akan menimbulkan dampak bagi masyarakat. Salah satunya terhentinya siklus hidup biota di sekitar hutan mangrove yang mengakibatkan pendapatan nelayan berkurang sehingga tidak dapat memenuhi kebutuhan hidupnya dan dapat meningkatkan angka kemiskinan di daerah pesisir.

Ekosistem hutan mangrove juga dapat mempengaruhi hasil produksi tambak. Untuk tambak bandeng menghasilkan nilai guna sebesar Rp 320.000.000,-/tahun dan tambak udang sebesar Rp 312.000.000,-/tahun. Sedangkan tambak garam memperoleh hasil lebih rendah yaitu sebesar Rp 18.000.000,-/tahun karena untuk produksinya sendiri bergantung dengan musim.

\section{Nilai Pilihan (Option Value/OV)}

Nilai pilihan ekosistem hutan mangrove dihitung menggunakan perkiraan dari nilai yang dihasilkan oleh suatu sumber daya alam yang ada di tempat lain, kemudian nilai tersebut digunakan sebagai gambaran manfaat dari suatu lingkungan. Menurut Ruitenbeek (1992) Nilai biodiversity hutan mangrove di Indonesia mempunyai nilai sebesar US\$1,500 per $\mathrm{km}^{2}$ atau US $\$ 15 / \mathrm{ha} / \mathrm{th}$. Nilai ini merupakan asumsi yang dapat digunakan untuk seluruh hutan mangrove di Indonesia yang terjaga secara alami. Nilai dari manfaat biodiversity didapatkan dengan cara mengalikan kurs dolar sebesar Rp 14.072,39 (16 November 2019) dengan luasan hutan mangrove sebesar 81,332 ha. Berdasarkan perhitungan tersebut nilai pilihan di Desa Betahwalang adalah sebesar $\mathrm{Rp}$ 17.168.034,35/tahun.

\section{Nilai Keberadaan (Existence Value/EV)}

Nilai keberadaan hutan mangrove diperoleh dari adanya kesedian masyarakat untuk membayar suatu kondisi lingkungan dalam rangka memperbaiki kualitas lingkungan agar dapat berfungsi sebagai mestinya. Nilai keberadaan ekosistem hutan mangrove di Desa Betahwalang adalah sebesar Rp 612.576.000,-/tahun yang dihitung dari hasil perkalian WTP (Willness to Pay) masyarakat sebesar Rp 108.000,-/tahun dengan jumlah penduduk sebanyak 5.672 orang. Nilai WTP ini menggambarkan besarnya biaya minumum yang seseorang bayarkan dalam bentuk kepuasan terhadap suatu sumberdaya alam yang dapat memberikan manfaat bagi masyarakat.

\section{Nilai Warisan (Bequest Value/ BV)}

Menurut Ruitenbeek (1992) nilai warisan ekosistem hutan mangrove diperkirakan berasal dari $10 \%$ dari nilai manfaat langsung yang dihasilkan oleh adanya ekosistem hutan mangrove. Nilai guna langsung di Desa Betahwalang sebesar Rp 800.275.000,-/tahun sehingga nilai warisan dari ekosistem hutan mangrove adalah sebesar Rp 80.027.500,-/tahun. Nilai warisan ini merupakan bentuk kepedulian masyarakat saat ini terhadap generasi yang akan datang. Semakin tinggi kepedulian masyarakat dalam menjaga keberadaan ekosistem hutan mangrove maka semakin tinggi pula peluang generasi yang akan datang untuk merasakan adanya fungsi dan manfaat ekosistem hutan mangrove di masa depan.

\section{Nilai Ekonomi Total (Total Economic Value/ TEV)}

Nilai ekonomi total (TEV) merupakan nilai yang didapatkan dari hasil penjumlahahan keseluruhan nilai ekonomi yang terkandung di dalam ekosistem hutan mangrove. Nilai-nilai tersebut berasal dari nilai guna langsung, nilai pilihan, nilai keberadaan dan nilai warisan yang telah diidentifikasi dan dikuantifikasikan. Nilai ekonomi total yang terdapat di Desa Betahwalang adalah sebesar Rp 1.510.046.534,-/tahun yang didapatkan dari nilai guna (use value) sebesar Rp 
817.443.034,35,-/tahun yang terdiri dari nilai guna langsung sebesar $\mathrm{Rp} 800.275 .000$,-/tahun dan nilai pilihan sebesar Rp 17.168.034,35,-/tahun. Nilai non guna (non use value) sebesar Rp 692.603.500,-/tahun terdiri dari nilai keberadaan sebesar $\mathrm{Rp} 612.576 .000$,-/tahun dan nilai warisan sebesar Rp 80.027.500,-/tahun.

Tabel 1. Nilai Total Ekonomi Ekosistem Hutan Mangrove di Desa Betahwalang, Kecamatan Bonang, Kabupaten Demak

\begin{tabular}{|c|c|c|c|}
\hline No. & Jenis Nilai Guna & Nilai Total (Rp) & Persentase (\%) \\
\hline \multirow[t]{3}{*}{1.} & Nilai Guna (Use Value) & & \\
\hline & Nilai Guna Langsung & 800.275 .000 & 53 \\
\hline & Nilai Pilihan & $17.168 .034,35$ & 1.10 \\
\hline \multicolumn{2}{|c|}{ Use Value } & Rp 817.443.034,35 & \\
\hline \multirow[t]{3}{*}{2.} & $\begin{array}{l}\text { Nilai Non Guna } \\
\text { (Non Use Value) }\end{array}$ & & \\
\hline & Nilai Keberadaan & 612.576 .000 & 40.60 \\
\hline & Nilai Warisan & 80.027 .500 & 5.30 \\
\hline \multicolumn{2}{|c|}{ Non Use Value } & Rp 692.603 .500 & \\
\hline \multicolumn{2}{|c|}{ Total Nilai Ekonomi } & Rp 1.510.046.534 & 100 \\
\hline
\end{tabular}

Berdasarkan nilai ekonomi total diatas dengan dengan luas ekosistem mangrove sebesar 81.332 ha menunjukkan bahwa nilai guna langsung ekosistem mangrove di Desa Betahwalang memiliki peranan yang sangat penting karena memiliki persentase nilai yang paling besar kemudian diikuti nilai keberadaan, nilai pilihan dan nilai warisan. Hal ini sesuai dengan pendapat responden yang dijumpai, bahwa ekosistem hutan mangrove di Desa Betahwalang memberikan dampak posistif secara langsung bagi masyarakat di wilayah pesisir. Salah satu dampak posistif yang dirasakan masyarakat adalah persediaan hasil perikanan yang melimpah. Sebagaimana diketahui bahwa ekosistem hutan mangrove mempunyai manfaat secara ekologis yaitu sebagai tempat mencari makan dan perlindungan berbagai biota laut. Jika dibandingkan dengan penelitian Simbala et al. (2017) di Tanjung Dudepo, Sulawesi Utara mempunyai nilai ekonomi total sebesar Rp 1.677.932.338,-/tahun yang nilainya lebih besar dari Desa Betahwalang. Perbedaan yang terjadi pada penelitian-penelitian sejenis diduga karena kondisi ekosistem hutan mangrove, luasan ekosistem hutan mangrove, perubahan nilai tukar rupiah US\$, perbedaan harga pasar dan pemanfaatan yang dilakukan masyarakat di sekitar ekosistem hutan mangrove.

Nilai manfaat pada ekosistem hutan mangrove bergantung dengan keberadaan ekosistem hutan mangrove itu sendiri. Apabila terjadi pemanfaatan secara terus-menerus akan terjadi tekanan terhadap sumberdaya alam di dalam maupun di sekitar ekosistem hutan mangrove yang menyebabkan kerusakan. Fungsi ekosistem mangrove akan tetap ada jika masyarakat menjamin keberadaan ekosistem hutan mangrove dengan baik. Sebaliknya jika tidak masyarakat akan mengalami kerugian yang berpengaruh terhadap tingkat kesejahteraan. Dengan demikian masyarakat setempat harus menjaga kondisi ekosistem hutan mangrove agar dapat berfungsi sebagaimana mestinya serta melakukan pemanfaatan secara konservatif dan tidak mengeksploitasinya.

\section{KESIMPULAN}

Berdasarkan hasil penelitian kajian valuasi ekonomi ekosistem hutan mangrove di Desa Betahwalang, Kecamatan Bonang, Kabupaten Demak dapat dapat disimpulkan bahwa nilai guna (use value) dari ekosistem hutan mangrove sebesar Rp 817.443.034,35/tahun yang didapatkan dari nilai guna langsung dan nilai guna pilihan. Sedangkan nilai non guna (non use value) sebesar $\mathrm{Rp}$ 692.603.500/tahun yang didapatkan dari nilai keberadaan dan nilai warisan. Dengan demikian nilai total ekonomi (total economic value) ekosistem hutan mangrove di Desa Betahwalang adalah sebesar Rp 1.510.046.534/tahun 


\section{DAFTAR PUSTAKA}

Arikunto, S., 2002. Prosedur Suatu Penelitian: Pendekatan Praktek. Edisi Revisi Kelima. Penerbit Rineka Cipta. Jakarta.

Amalia, A.C., 2011. Kajian Program Rehabilitasi Mangrove Di Desa Kaliwlingi, Kecamatan Brebes, Kabupaten Brebes, dan Desa Bedono, Kecamatan Sayung, Kabupaten Demak, Jawa Tengah. Diponegoro Journal of Maquares, 4(3):139-147.

Ekosafitri, K.H., Rustiadi, E. \& Yulianda, F., 2017. Pengembangan Wilayah Pesisir Pantai Utara Jawa Tengah Berdasarkan Infrastruktur Daerah: Studi Kasus Kabupaten Jepara. Journal of Regional and Rural Development Planning, 1(2):145-157. DOI : 10.29244/jp2wd.

Faturohmah, S. \& Marjuki, B., 2017. Identifikasi Dinamika Spasial Sumberdaya Mangrove di Wilayah Pesisir Kabupaten Demak Jawa Tengah. Majalah geografi Indonesia, 31(1): 56-64. DOI : 10.22146/MGI.24234.

Ganesa, A.S., 2019. Areal Mapping di Desa Betahwalang, Kecamatan Bonang, Kabupaten Demak. Aksa Jaladhi Angkasatama.

Gholizadeh, M.H., Melesse, A. \& Reddi, L., 2016. A Comprehensive Review on Water Quality Parameters Estimation Using Remote Sensing Techniques. Sensors, 16(8):1298-.... DOI: $10.3390 / \mathrm{s} 16081298$.

Isman, M., Rani, C., Haris, A. \& Faizal, A., 2019. Sebaran dan Kondisi Ekosistem Perairan di Pulau Panampeang Polowali Mandar., Jurnal IImu Kelautan Spermonde 5(1):16-20. DOI: 10.20956/Jiks.v5i1.7028.

Purnama, M., Pribadi, R., dan Soenardjo. 2020 . Struktur Komposisi dan Tutupan Vegetasi Mangrove di Desa Betahwalang, Kecamatan Bonang, Kabupaten Demak, Jawa Tengah. Journal of Marine Research, 9(3):317-325.

Pujihastuti, I., 2010. Prinsip Penulisan Kuesioner Penelitian. Jurnal Agribisnis dan Pengembangan Wilayah, 2(1):43-56.

Ruitenbeek, H.J., 1991. Mangrove Management: An Economic Analysis of Management Option with a Focus on Bituni Bay, Irian Jaya. Menteri Negara Kependudukan dan Lingkungan Hidup. Jakarta

Ruitenbeek, H.J., 1992. Mangrove Management: An Economic Analysis of Management Option with a Focus on Bintuni Bay, Irian Jaya. Environmental Management Development in Indonesia (EMD) Project. EMDI Environmental. Jakarta.

Tuwo, A., 2011. Pengelolaan Ekowisata Pesisir dan Laut (Pendekatan Ekologi, Sosial - Ekonomi, Kelembagaan, dan Sarana Wilayah). Penerbit Brilian Internasional. Yogyakarta.

Yuliani, S. \& Herminasari, N.S., 2017. Partisipasi Masyarakat Dalam Pengelolaan Hutan Mangrove Di Desa Segara Jaya, Kecamatan Tarumajaya Kabupaten Bekasi. Jurnal Green Growth dan Manajemen Lingkungan, 6(2):42-45. DOI : 10.21009/jgg.062.04.

Zen, L.W. \& Ulfah, F., 2013. Valuasi Ekonomi Hutan Mangrove Di Pulau Dompak Kota Tanjung Pinang Provinsi Kepulauan Riau. Jurusan Manajemen Sumberdaya Perairan Universitas Maritim Jaya Ali Haji. Tanjung Pinang. Jurnal Dinamika Maritim, 4(1):45-52. DOI : 10.31186/jgg.21.115. 